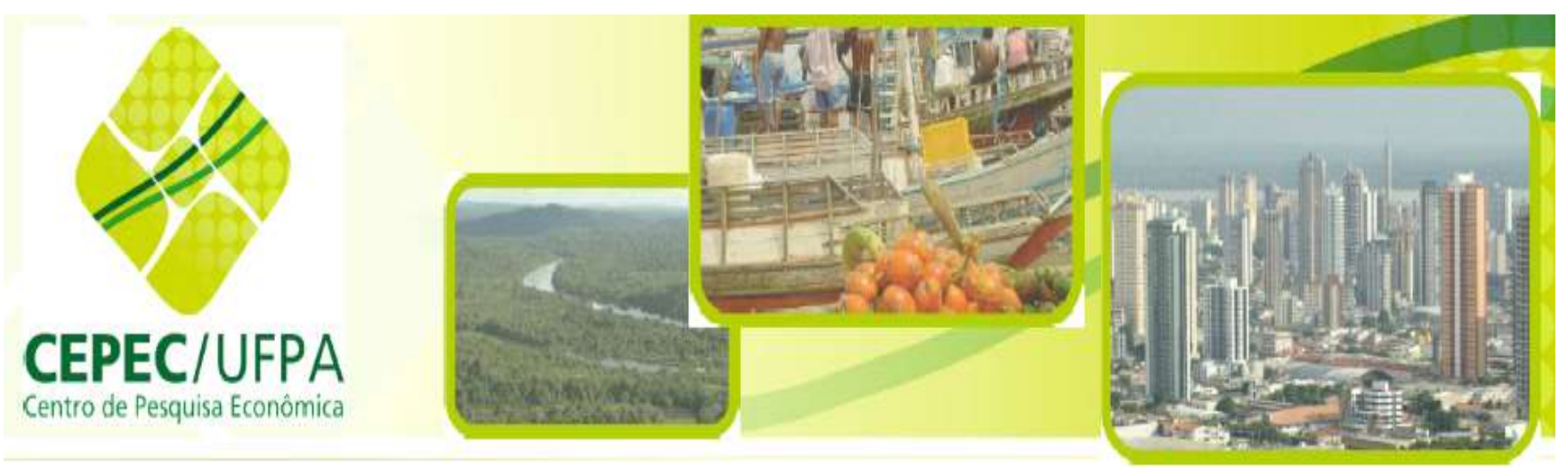

\title{
ISSN 2238-118X
}

\section{CADERNOS CEPEC}

\section{6 N.6 Junho de 2017}

O PROCESSO DE IMPLANTAÇÃO DE ÁREAS DE "REFLORESTAMENTO" NO MUNICÍPIO DE AÇAILÂNDIA/MA: perspectivas e conflitos sobre o plantio do eucalipto como estratégia de desenvolvimento

Lia Renata Costa Gomes

Centro de Pesquisas Econômicas da Amazônia

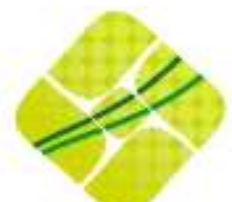




\section{CADERNOS CEPEC}

Publicação do Programa de Pós-graduação em Economia da Universidade Federal do Pará Periodicidade Mensal - Volume 6-N ${ }^{\circ}$ 06-Junho (Especial V Seminário Amazônias) 2017

Reitor: Emmanuel Zagury Tourinho

Vice Reitor: Gilmar Pereira da Silva

Pró-Reitor de Pesquisa e Pós Graduação: Rômulo Simões Angélica

Instituto de Ciências Sociais Aplicadas

Diretor: Carlos Alberto Batista Maciel

Vice Diretor: Manoel Raimundo Santana Farias

Coordenador do Mestrado e Doutorado em Economia: Ricardo Bruno Nascimento dos Santos

\section{Editores}

José Raimundo Barreto Trindade - Principal

Sérgio Luis Rivero

Conselho Editorial

Armando Lírio de Souza Marcelo Bentes Diniz

Ricardo Bruno dos Santos
Francisco de Assis Costa José Raimundo Trindade Danilo de Fernandes
Gilberto de Souza Marques Sérgio Luis Rivero

Gisalda Filgueiras Márcia Jucá Diniz
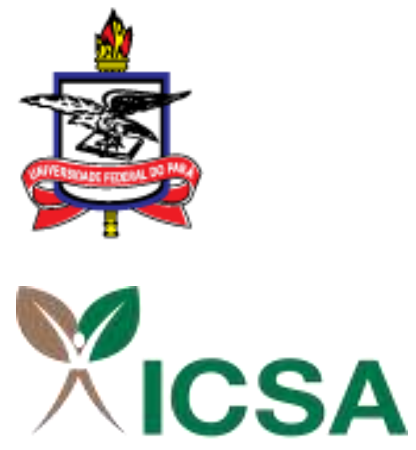

Instituto de Ciéncias Sociais Aplicadas
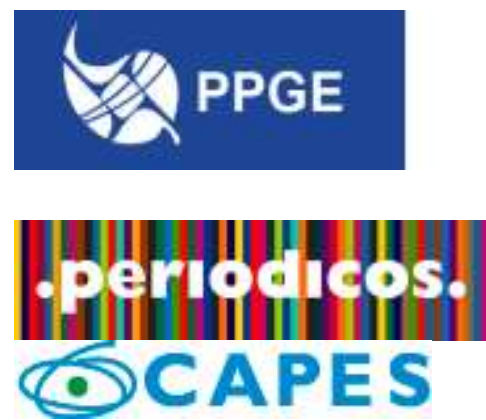


\section{Cadernos CEPEC Missão e Política Editorial}

Os Cadernos CEPEC constituem periódico mensal vinculado ao Programa de Pós-graduação em Economia do Instituto de Ciências Sociais Aplicadas (ICSA) da Universidade Federal do Pará (UFPA). Sua missão precípua constitui no estabelecimento de um canal de debate e divulgação de pesquisas originais na grande área das Ciências Sociais Aplicadas, apoiada tanto nos Grupos de Pesquisa estabelecidos no PPGE, quanto em pesquisadores vinculados a organismos nacionais e internacionais. A missão dos Cadernos CEPEC se articula com a solidificação e desenvolvimento do Programa de Pós-graduação em Economia (PPGE), estabelecido no ICSA.

A linha editorial dos Cadernos CEPEC recepciona textos de diferentes matizes teóricas das ciências econômicas e sociais, que busquem tratar, preferencialmente, das inter-relações entre as sociedades e economias amazônicas com a brasileira e mundial, seja se utilizando de instrumentais históricos, sociológicos, estatísticos ou econométricos. A linha editorial privilegia artigos que tratem de Desenvolvimento social, econômico e ambiental, preferencialmente focados no mosaico que constitui as diferentes "Amazônias", aceitando, porém, contribuições que, sob enfoque inovador, problematize e seja propositivo acerca do desenvolvimento brasileiro e, ou mesmo, mundial e suas implicações.

Nosso enfoque central, portanto, refere-se ao tratamento multidisciplinar dos temas referentes ao Desenvolvimento das sociedades Amazônicas, considerando que não há uma restrição dessa temática geral, na medida em que diversos temas conexos se integram. Vale observar que a Amazônia Legal Brasileira ocupa aproximadamente 5,2 milhões de $\mathrm{Km} 2$, o que corresponde a aproximadamente $60 \%$ do território brasileiro. Por outro lado, somente a Amazônia brasileira detém, segundo o último censo, uma população de aproximadamente 23 milhões de brasileiros e constitui frente importante da expansão da acumulação capitalista não somente no Brasil, como em outros seis países da América do Sul (Colômbia, Peru, Bolívia, Guiana, Suriname, Venezuela), o que a torna uma questão central para o debate da integração sul-americana.

\section{Instruções para submissão de trabalhos}

Os artigos em conformidade a linha editorial terão que ser submetidos aos editorialistas, em Word, com no máximo 25 laudas de extensão (incluindo notas de referência, bibliografia e anexos). Margens superior e inferior de 3,5 e direita e esquerda de 2,5. A citação de autores deverá seguir o padrão seguinte: (Autor, data, página), caso haja mais de um artigo do mesmo autor no mesmo ano deve-se usar letras minúsculas ao lado da data para fazer a diferenciação, exemplo: (Rivero, 2011, p. 65 ou Rivero, 2011a, p. 65). Os autores devem fornecer currículo resumido. O artigo deverá vir obrigatoriamente acompanhado de Resumo de até no máximo 25 linhas e o respectivo Abstract, palavras-chaves e Classificação JEL (Journal of Economic Literature).

Este número especial deve-se ao V Seminário Amazônias realizado no período de 20 a 22 de setembro de 2016, organizado pelo Programa de Pós-graduação em Economia (PPGE) e Observatório Paraense do Mercado de Trabalho (OPAMET), os artigos publicados foram selecionados para participação no referido seminário.

Comentários e Submissão de artigos devem ser encaminhados ao

Centro de Pesquisas Econômicas da Amazônia, através do e-mail:

jrtrindade@uol.com.br

Página na Internet: https://goo.gl/UuiC84

Portal de Periódicos CAPES: https://goo.gl/tTKEB4 


\title{
O PROCESSO DE IMPLANTAÇÃO DE ÁREAS DE "REFLORESTAMENTO" NO MUNICÍPIO DE AÇAILÂNDIA/MA: perspectivas e conflitos sobre o plantio do eucalipto como estratégia de desenvolvimento
}

\author{
Lia Renata Costa Gomes ${ }^{1}$
}

\section{RESUMO}

O artigo busca propor um exercício reflexivo a partir de algumas discussões sobre o processo de desenvolvimento em suas diferentes perspectivas. Isso a partir da crítica e do ponto de vista de alguns autores que tratam o assunto. Abarca uma problemática acerca da retórica da globalização e seus efeitos sobre o mercado de trabalho. Tece algumas considerações sobre o processo de implantação de áreas de reflorestamento em Açailândia e seus impactos no mercado de trabalho local. Abarca uma problemática sob o uso da monocultura e a utilização de prestadoras de serviços para manutenção do processo de produção que vai do plantio a colheita, apontando simultaneamente que o crescimento econômico da indústria florestal acabou por ignora alguns problemas no que tange a criação de empregos precários e a degradação do meio ambiente. É um trabalho de base mais exploratória, tendo em vista que a pesquisa encontra-se em fase de andamento e aprimoramento.

Palavras-chave: Desenvolvimento. Globalização. Indústria Florestal. Relações de trabalho.

\section{ABSTRACT}

The article seeks to propose a reflexive exercise based on some discussions about the development process in its different perspectives. This is based on the criticism and the point of view of some authors who treat the subject. It covers a problematic about the rhetoric of globalization and its effects on the labor market. It makes some considerations about the process of implantation of reforestation areas in Açailândia and its impacts on the local labor market. It covers a problem under the use of monoculture and the use of service providers to maintain the production process that goes from planting to harvest, while pointing out that the economic growth of the forest industry has finally ignored some problems regarding the creation of precarious jobs and the degradation of the environment. It is a more exploratory groundwork, considering that the research is in progress and improvement phase.

Keywords: Development. Globalization. Forestry Industry. Work relationships.

\footnotetext{
${ }^{1}$ Graduada em ciências sociais pela Universidade Federal do Maranhão. Mestranda em Ciências Sociais do Programa de Pós-graduação em Ciências Sociais (PPGCSOC) da Universidade Federal do Maranhão. Email: 1-renat@hotmail.com/ liarenata.costagomes@gmail.com.
} 


\section{SUMÁRIO}

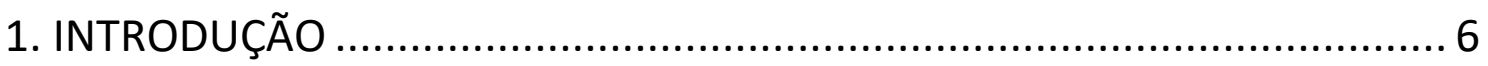

2 ALGUMAS PERSPECTIVAS SOBRE DESENVOLVIMENTO_......................... 9

2.1 A idealização do "sustentável", como instrumento de regulação ..... 12

2.2 A retórica da globalização: discursos, contradições e influências no mercado de trabalho .................................................................... 15

3 SOBRE O PLANTIO DO EUCALIPTO, COMO ESTRATÉGIA DE FUGA, O PROCESSO DE IMPLANTAÇÃO DO SETOR DE “REFLORESTAMENTO” EM

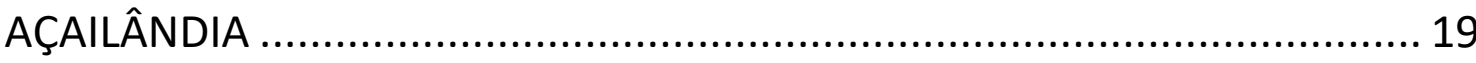

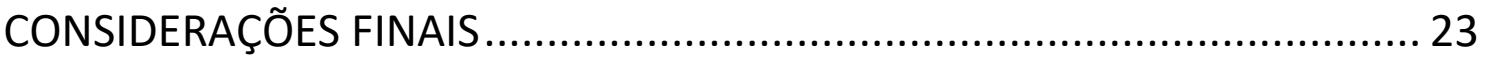

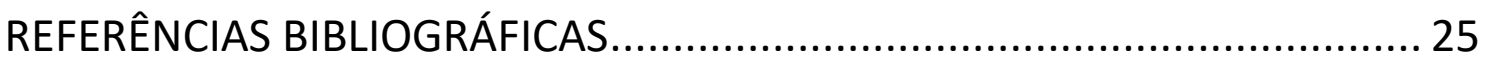




\section{INTRODUÇÃO}

Diante dos grandes projetos de desenvolvimento instalados na Amazônia brasileira, e seguindo a lógica de autores que buscam colocar em evidência a articulação entre "desenvolvimento e meio ambiente" (ZHOURI; LASCHEFSKI, 2010), por causa de um processo desenfreado que trouxe graves consequências ambientais e sociais. Frente a isso, entra em cena alguns movimentos de combate aos planos de um progresso sem controle, posto que, os contextos de desenvolvimento visavam inserir "estratégias de modernização no país", que pudessem estabelecer uma ordem de composição e reconstrução de "instituições sociais", e da mesma forma, a aplicação de recursos para promover um sistema de serviços de "transporte", de "energia", assim como de uma "indústria de base", a fim de estimular um processo de crescimento econômico. No curso em que se deu todo o processo, se esperava que a sociedade brasileira de um modo geral, fosse beneficiada, com a criação de novos postos de trabalho e "geração de renda", mas o que se viu foi o contrário.

A idealização do "desenvolvimento" deu o alvará para que áreas que eram, exclusivamente, "cobertas pela vegetação natural", fossem visadas pelo mercado capitalista, como "espaços" que pudessem ser explorados e ocupados "por grandes empreendimentos agroexportadores ou complexos industriais, como o de Grande Carajás, na Amazônia Legal" (ZHOURI; LASCHEFSKI, 2010, p.11). Não obstante, não se efetivou o que foi prometido com o lançamento das propostas "desenvolvimentistas". O que se pôde perceber foi que, com grandes projetos de desenvolvimento também vieram os mais variados problemas. Causadores do aumento do "desemprego estrutural nos centros urbanos, conflitos fundiários e formas de exclusão de grupos marginalizados, além da devastação ambiental" (Ibid, p.12).

A ideia constante da indispensabilidade do desenvolvimento, foi ganhando cada vez mais extensão, através de um processo historio ideológico, de construção de uma representação mental de sua necessidade. Em contextos de crescimento econômico, ignora-se a possibilidade de existir "bem-estar social" sem os avanços tecnológicos e o desenvolvimento das forças produtivas. Em meio às consequências visíveis, causadas pela exploração excessiva aos recursos naturais, se percebe um movimento contrário a essa lógica. Isso possibilita a busca de mecanismos ou medidas de conservação. A mobilização de grupos contrários à ideologia do desenvolvimento faz emergir sempre 
novas formas de pensar o desenvolvimento. Todavia, sua efetivação, não muda as perspectivas que se tem sobre a necessidade do desenvolvimento. A própria noção de "sustentável" é assim pensada, como um meio de estabelecer um processo conciliador entre a conservação do meio ambiente e extensão da produção capitalista.

As empresas do setor siderúrgico, implantadas no município de Açailândia, através de incentivos do Programa Grande Carajás (PGC), que vieram com grandes promessas de desenvolvimento e geração de emprego, ocasionaram sérios problemas sociais e ambientais. Foi a partir da mobilização dos mais diferentes "atores sociais", diante dos dilemas e impasses causados pelo setor, que algumas medidas foram tomadas. As empresas acionaram mecanismos para fugir às criticas e criaram o setor de "reflorestamento", com a utilização da monocultura, através do plantio do eucalipto. Contudo, por um lado, fez reduzir a utilização de trabalhadores em situação de escravidão e o processo de devastação ambiental. Mas, por outro, tem todas as consequências causadas pela utilização da monocultura e pela terceirização da mão de obra.

O município de Açailândia, segundo Carneiro (1997), tem seu momento de desenvolvimento a partir de duas perspectivas, que estão relacionadas ao curso de migrações no município. Primeiramente de trabalhadores vindos do nordeste, que chegam ao município, a partir dos anos 1960, saindo em busca de extensões de terra para plantação e cultivos agrícolas. E outra, oriunda de pessoas vindas da região de Minas Gerais, através da rota Belém - Brasília. Contudo, os dois grupos de imigrantes possuíam características distintas. Isso porque, um grupo, trazia na bagagem a experiência com o trabalho agrícola, enquanto o outro, não possuía o mesmo traquejo. Todavia, mesmo um dos grupos não possuindo habilidades com a plantação de cultivos agrícolas, eles possuíam algum tipo de bem econômico, que possibilitou sua instalação na cidade, através do uso de atividades relacionadas ao comércio e a pequenos estabelecimentos industriais.

É nesse período, que o município de Açailândia começou a passar por um processo de transformação. Adquiriu novas configurações e tornou-se mais visado por um mercado vasto, com políticas voltadas ao desenvolvimento. Desse modo, é nesse ciclo, segundo Moura (2006), que as formas de escravidão moderna começam a ganhar evidência, e a região amazônica passou a ser mais ambicionada pelo mercado. Uma vez que, na busca desenfreada por explorar o máximo de recursos naturais, a fim de favorecer o aumento do capital e, dos bens de produção, os empresários apostaram de 
maneira extensiva em negócios na região amazônica. Todo o processo contribuiu para que centenas de trabalhadores fossem contratados de forma irregular, e submetidos a trabalhos precários, do mesmo modo que, ocasionou uma extensiva devastação ambiental.

Com a entrada de recursos e subsídios vindos do Programa Grande Carajás, para o desenvolvimento dos parques industriais, de acordo com Carneiro (2009) foi disponibilizada também, através da SUDAM (Superintendência de Desenvolvimento do Nordeste) a aplicação de políticas públicas no município. Os empreendimentos, implantados no setor da indústria de transformação no município de Acailândia, ganham dimensões influentes, que ocorrem por contam dos conflitos agrários nas fazendas. É o momento em que o setor agropecuário deu lugar às carvoarias. Elas passaram a ser contempladas, pelos mais diferentes empresários do setor siderúrgico, por conta da necessidade que o setor tem do carvão vegetal, como matéria prima para ser utilizada na produção de ferro gusa.

Nesse âmbito, o que segue é uma análise sobre o processo de desenvolvimento. Na primeira seção seguinte a esta introdução, aborda-se as diferentes formas que o mito do desenvolvimento assume, como, por exemplo, o "desenvolvimento sustentável”, assim como o complexo jogo de palavras entre a noção de desenvolvimento e a de subdesenvolvimento. Isso a partir da crítica e perspectivas de alguns autores que tratam o assunto. Abarca, ainda, uma problemática acerca da retórica da globalização e seus efeitos sobre o mercado de trabalho. Na seção seguinte, realiza-se a discussão da problemática do uso da monocultura do eucalipto como forma de "reflorestamento", porém o que se percebe, são subterfúgios para manutenção do processo de produção, e simultaneamente o crescimento econômico que ignora os diversos problemas que esse tipo de método traz ao meio ambiente. Por fim, esforça-se também por apresentar uma ótica da implantação do setor de "reflorestamento" no município de Açailândia, os dilemas, conflitos e discussões surgidos entorno da problemática em questão. 


\section{ALGUMAS PERSPECTIVAS SOBRE DESENVOLVIMENTO}

Ao pensar no "campo do desenvolvimento", Zhouri (2012) aponta as perspectivas de como se constituir uma rede de "atores sociais" que se articulam nos mais diferentes contextos. Esses "atores" podem ser tanto "elites locais, como lideres de movimentos sociais", com interesses comuns ou distintos. Dessa forma, as "instituições" tem um papel fundamental no "campo do desenvolvimento", envolvendo "vários tipos de organizações governamentais organizações não governamentais (ONGs), igrejas, sindicatos, agências multilaterais, entidades industriais e corporações financeiras” (p. 199).

Em nome do desenvolvimento, na análise de Escobar (1995 apud RADOMSKY, 2011), alguns fatores como o saber local, ou a forma como determinadas comunidades lidam com e apreendem a natureza, são desconsiderados quando o fator preponderante são as relações de mercado. O que ocorre é que as "agências", ou os países ditos "desenvolvidos", ou até mesmo o "aparelho estatal", mantêm um olhar de cima para baixo, levantando os dilemas, impasses e discrepâncias sobre mudanças que precisam ocorrer, para suprir a "falta" de algo, que eles acreditam ter nos países periféricos. Porém, o que acontece de fato é que os elementos essenciais para aplacar as "desigualdades sociais" são ignorados e, em muitos casos, até agravadas pelo crescimento econômico desigual e excludente. O que se mede não são as concepções acerca dos fatores essenciais para promover o "bem-estar" das pessoas, porém, uma estatística que quantifica e suprime as necessidades básicas das pessoas, em favor do progresso ou do aumento da produção.

Em uma sucessão de operações realizadas por aqueles que têm interesse direto em manter o avanço da produção e o crescimento econômico, está às estratégias de convencimento e retirada de populações tradicionais, que resistem às ideologias do desenvolvimento. Nesse contexto, de acordo com Radomsky (2011), é possível perceber a atuação de antropólogos, como mediadores entre as comunidades resistentes e as "agências de desenvolvimentos". Deles é exigido, dessa forma, uma postura de compreensão das "necessidades das agências" e também dos "governos" que, por outro lado, ignoram a situação daqueles que serão atingidos diretamente com as possíveis "mudanças".

Todo esse contexto de transformação e imposição de políticas modernas alterou a dinâmica dos espaços em várias partes do mundo. O que não deixa de ser uma forma 
agressiva de estabelecer as coisas, sem levar em consideração todo o contexto histórico e cultural que cada espaço possuiu de forma singular como herança. O processo de globalização, que visa manter entre as muitas partes do mundo uma interação cultural global, deve ser encarado como o mecanismo que produz ideologias que se tornam persistente porque são constantemente prescritas. Essa homogeneização cultural nada tem de positivo, até porque, o que se busca é padronizar as diversas partes do mundo, subtraindo delas, riquezas muitas vezes imensuráveis. É um erro achar que todo um conjunto de símbolos construídos ao longo de um processo histórico, deva entrar de qualquer forma na dinâmica prescrita pelo desenvolvimento.

Em conformidade com as perspectivas de análises traçadas por Furtado (2003), o "desenvolvimento econômico" contemporâneo, raramente aconteceria, sem que houvesse a participação de uma grande parcela da "massa populacional". Assim sendo, quando se coloca em cheque uma verdadeira proposta de "política de desenvolvimento", é factível perceber, como o conceito de desenvolvimento gira em torno de um ponto de vista, que coloca como fator fundamental as convicções acerca de um desejo de progresso vindo não apenas de pequenos grupos, mas de uma "coletividade" ${ }^{2}$. Com isso, se transfere para a sociedade de um modo geral, a responsabilidade de sustentar, que o crescimento econômico é uma vontade comum de todos. Nesse aspecto, caberia aos "órgãos públicos" competentes, elucidar as ânsias da "coletividade", a respeito do desenvolvimento, a fim de garantir, sua contínua atuação, sem os pormenores e impedimentos.

A dicotomia entre o significado das palavras "desenvolvido" e "subdesenvolvido" dá-se segundo Esteva (2000), a partir do "discurso do presidente Truman" no momento de sua posse em 20 de janeiro de 1949, na intenção de estabelecer uma preeminência do posicionamento dos "norte-americanos" frente ao mundo. Isso instituiu uma separação entre países considerados desenvolvidos e países que, segundo a lógica do crescimento econômico, são vistos como carentes de desenvolvimento ou "subdesenvolvidos". Ao mesmo tempo em que separou, lançou bases para se pensar os países como "periféricos" e necessitados de um processo de

\footnotetext{
¿“ $\mathrm{O}$ ponto de partida do estudo do desenvolvimento deveria ser não a taxa de investimento, ou a relação produto-capital, ou a dimensão do mercado, mas o horizonte de aspirações da coletividade em questão, considerada não abstratamente, mas como um conjunto de grupos ou estratos com perfil definido. $\mathrm{O}$ desenvolvimento é a transformação do conjunto das estruturas de uma sociedade em função de objetivos que se propõe alcançar essa sociedade" (FURTADO, 2003, p. 103).
} 
modernização e de inserção de políticas capazes de garantir crescimento econômico. A concepção de "desenvolvimento" torna-se tão preponderante, que "ocupa o centro de uma constelação semântica incrivelmente poderosa. Não há nenhum outro conceito no pensamento moderno que tenha influência comparável sobre a maneira de pensar o comportamento humano" (p. 61).

Partindo desse pressuposto, o que se nota é que o "discurso de Truman" fez com que se conjecturasse um movimento mundial, que pudesse tomar conta de todos os espaços de forma hegemônica. Isso criou uma falsa ideia de que o mundo caminha num só movimento e que esse movimento é liderado por uma perspectiva de desenvolvimento contínuo. É um entendimento que deixa de lado um conjunto de outros aspectos fundamentais para a grande diversidade presente no mundo, a partir do que cada sociedade, grupo ou comunidade construiu como seu legado cultural e social.

A inerência da questão acerca de como se deu a gênese, os processos, demandas e razões vigentes do "subdesenvolvimento" seguindo os pressupostos de Esteva (2000), indicam como o "subdesenvolvimento" torna-se reconhecido, "como algo real, concreto, quantificável e identificável" (p. 66). O sentido que se dar a ideia construída em torno do discurso do que venha a ser "subdesenvolvido", elucida os aspectos da sua noção. Favorecendo que, o ponto de vista, no que lhe concerne à imagem de "subdesenvolvimento", se reverta em "um objeto" ou uma realidade. É tão forte e presente seu aparato conceitual que faz com as pessoas acreditem que, deveras, trata-se de algo efetivamente existente na prática. Quando na verdade, encobre a ocorrência de que se trata apenas uma abstração. Que por sua vez, exterioriza e manifesta uma "falsa noção da realidade".

Furtado (2003) julga em sua análise, que a ideia de "subdesenvolvimento" está continuamente atrelada à concepção de que sua gênese é resultado ou produto do "desenvolvimento". Isso, segundo um processo histórico, que considera a influência dos mais variados "impactos" sobre um amplo conjunto de "sociedades", assim como de "processos técnicos e de formas de divisão do trabalho irradiados de pequeno número de sociedades que se haviam inserido na revolução industrial em sua fase inicial, ou seja, até fins do século XIX” (p. 88). Seguindo ainda a dimensão da apreciação de Furtado como relação à ideia de "subdesenvolvimento" como consequência do "desenvolvimento", constata-se um encadeamento que faz surgir à noção de “dependência”. Que em seu prelúdio, encontra suporte "num sistema de divisão 
internacional do trabalho, que reservava para os centros dominantes as atividades produtivas em que se concentrava o progresso tecnológico" (Ibid, 2003).

De acordo com Shiva (2000), com a transgressão das fronteiras para exploração dos "recursos naturais", se faculta a circunstâncias para os estágios contemporâneos que encaram as etapas instáveis do "desenvolvimento" a partir dos princípios do que vem a ser "desenvolvimento sustentável" e "crescimento sustentável" (p. 301). Desse modo, se preconiza uma relação que visa estabelecer os marcos dos "processos naturais", na intenção de dar continuidade ao processo de "desenvolvimento" e "crescimento econômico". O que se verifica em momentos recentes, é que se coloca em cheque uma ideia de "escassez", que ora é pensada como um aspecto relevante a ser observado, e por isso, se investe na à ideia de "sustentabilidade". E ora, de forma simultânea, nota-se um verdadeiro descaso em nome do desenvolvimento, do valor que tem a "natureza" como algo "sagrado", e que, portanto, precisa ser preservada.

Em vista disso, o que segue é uma tentativa de levantar algumas ideias que permitam pensar as propostas e críticas em torno da ideia de desenvolvimento sustentável, como estratégia para conciliar crescimento econômico e preservação ambiental.

\subsection{A idealização do "sustentável", como instrumento de regulação}

Em meio aos conflitos e lutas contra as "estratégias de desenvolvimento" sem grande controle e aos protestos de grupos e movimentos ambientalistas, nasce à ideia de "desenvolvimento sustentável" que vem atrelada a uma perspectiva de conciliação entre a expansão econômica, adequada a uma suposta preservação dos recursos naturais. A expressão "sustentável" foi assim tomada, não da forma como foi pensada e desejada inicialmente. Até mesmo porque a própria ideia de "desenvolvimento" e progresso econômico denota uma série de fatores que, em linhas gerais, visam explorar ao máximo os recursos naturais. Observa-se nesse processo um "paradigma” que, por um lado, coloca em evidência um parecer de que é necessário preservar o meio ambiente em favor do bem comum e, do outro, de que o progresso e o desenvolvimento econômico são necessários. O "sustentável", assumiria nesse caso, o papel de agregar, ou harmonizar desenvolvimento e sustentabilidade. 
Diante desse "paradigma", entram em debate as diversas formas de controle, no intuito de promover mecanismos de regulação para dar embasamento à noção de “desenvolvimento sustentável”. Nesse aspecto, sublinha-se:

A criação de fóruns internacionais, nacionais e locais para discutir a questão, a introdução de esquemas de avaliação ambiental nas instituições financeiras internacionais, com a subsequente criação de instituições ambientais, mecanismos de licenciamento ambiental, reforço da legislação ambiental e ênfase na educação ambiental em geral (ZHOURI, LASCHEFSKI, 2010, p. 13).

E em outros setores, como o "privado", se elenca iniciativas de desenvolvimento com a implantação de "tecnologias" que trazem a promessa de serem mais sustentáveis. Legitimando dessa forma, a atuação dos "empresários" que produzem um discurso de "responsabilidade" com o meio ambiente, mas que, na prática, não reduzem os danos causados pelo processo de produção em suas empresas.

No âmbito em que se constroem as diversas ideias sobre o desenvolvimento. Zhouri (2012) segue uma linha de pensamento que demonstra a forma como a conjuntura do crescimento econômico foi criando "numerosos adjetivos" para emergência do desenvolvimento. Isto posto, construiu-se também, "parte da sua história: industrial, capitalista, para dentro, para fora, comunitário, desigual, dependente, sustentável, humano. Essas variações e tensões refletem não apenas as experiências históricas acumuladas, por diferentes grupos de poder em suas lutas por hegemonia internamente ao campo do desenvolvimento, mas também diferentes momentos de integração do sistema capitalista mundial" (p. 214).

Por esse ângulo, a intenção do desenvolvimento é dar legitimidade as formas de exploração dos recursos naturais, sem que isso seja encarado como um dano à manutenção da vida de um modo geral. Não obstante, a ideia de desenvolvimento vem acompanhada por uma concepção de que onde não há crescimento econômico é que a vida corre o risco de está comprometida. Por consequência, é tão influente sua representação, que faz com que se acredite que contextos tradicionais, onde os aspectos da vida e da preservação dos recursos naturais são assim fatores fundamentais, sejam vistos como "atrasados". Uma lógica capitalista que submete todos os contextos ao seu processo de progressão do capital.

Nos pressupostos de Carneiro (2005), a proposta de "desenvolvimento sustentável" é contraditória, visto que na lógica do capitalismo, a exploração dos recursos naturais é um fator preponderante. Outra questão posta, é que a ideia de "sustentável" em seu discurso, visa à diminuição das disparidades sociais e o aumento 
do acesso aos "recursos naturais". Todavia, o que ocorre é que, "o capitalismo produz sistematicamente a desigualdade ecológica entre as nações e, dentro de cada uma delas, entre classes e grupos sociais" (p. 36). Além de não promover a distribuição dos "recursos naturais", e propagar o aumento das desigualdades sociais, as iniciativas capitalistas consolidam empreendimentos que buscam potencializar ainda mais, o aproveitamento das riquezas disponíveis na natureza, a favor de um crescimento econômico em constante disputa e movimento.

Embora existam alguns grupos que fazem o esforço para encontrar formas de preservação ambiental, por intermédio de uma conciliação entre a esfera econômica e a preservação do meio ambiente, o que se percebe é que, mesmo através da "ação do Estado", ou das "consequências das atividades econômicas voltadas à acumulação de capital, a sustentabilidade das práticas de reprodução material e simbólica de diferentes populações vê-se ameaçadas" (Ibid, p. 17). Pode até existir um discurso de preservação, mas na prática, e em nome do desenvolvimento, as questões relacionadas à manutenção do "bem-estar social" ou à conservação e proteção dos recursos naturais são deixados em segundo plano, com vistas à manutenção da produção. A própria atuação do Estado é ambígua, porque, de um lado, apresenta propostas de "políticas" que estimulam os mais diferentes "conflitos ambientais". E, por outro, aparece como um regulador das "populações atingidas".

De acordo com Escobar (2005), a concepção de "lugar" ganha um espaço periférico dentro das concepções produzidas pelas "teorias da globalização". O "lugar" que se revela para muitas comunidades tradicionais com o sentido de "pertencimento" e de "identidade" perde seu espaço para as questões de caráter puramente econômico, que por sua vez, ignora todo o aparato histórico e toda a "memória coletiva" construída ao longo dos tempos. Destarte, "o lugar, em outras palavras, desapareceu no "frenesi da globalização" dos últimos anos, e este enfraquecimento do lugar tem consequências profundas em nossa compreensão da cultura, do conhecimento, da natureza, e da economia. Talvez seja o momento de reverter algumas destas assimetrias, ao enfocar novamente a constante importância do lugar e da criação do lugar, para a cultura, a natureza e a economia" (p. 63). Nessa perspectiva, considera-se importante mensurar de maneira sintética, alguns aspectos da globalização, a fim de compreender como esse processo altera as dinâmicas do mundo inteiro. 


\subsection{A retórica da globalização: discursos, contradições e influências no mercado de trabalho}

É importante analisar e entender o fenômeno da globalização, assim como compreender como ele influencia diretamente a sociedade de um modo geral, e o mundo do trabalho. De acordo com Batista (1994), a globalização é um fenômeno econômico (abertura de mercados) em escala mais global. Esse processo consiste em uma integração em caráter econômico, social, cultural e político entre diferentes países. A globalização foi implantada no setor financeiro, com a liberação das reservas de mercado e dos fluxos de capital. É também a fase mais recente do capitalismo que se tornou predominante no mundo.

O processo de globalização, reforçado por políticas neoliberais, deixou no mundo inúmeras incertezas. O que se defende é que, com o capitalismo e os avanços da sociedade moderna, a vida dos indivíduos deu um salto para melhor, o que não é uma realidade, visto que, a maioria das pessoas apenas conhece o lado mais massacrante da moeda. O nível de pobreza é crescente, muitos vivem na miséria e em situações de risco ocasionadas por medidas políticas que só visam os mercados mundiais e o interesse de poucos. Essa felicidade tão ressaltada pelo processo de modernização nada tem de democrático, ao contrário, é totalmente impositivo e desumano, porque inclui alguns e exclui outros. Outro dado é que não dá para concluir que todos os países assumiram da mesma forma as políticas apontadas pelo processo de globalização, talvez um, como maior intensidade que outros.

Como afirma Batista (1994), a globalização, apresentou-se com ar de novidade, com discurso de oportunidade, de ampliação de mercados, internacionalização das culturas, informação, conexão do mundo pelos meios de comunicação, e melhorias para vida dos indivíduos. Essas supostas novidades limitaram-se às estratégias de mercados e aos meios de expansão mercantil, fomentados por grandes potências, sem a promoção de novas perspectivas de vida para as pessoas. Assim, com a chamada Revolução Industrial ou tecnológica, o intenso fluxo de informações, atropela a apreensão e interpretação particular dos fatos, pelas diversas sociedades.

Para seus ideólogos (ONU, BIRD, BID), globalizar seria integrar, tornar conhecidas as diversas dimensões sociais e econômicas mundiais. Seria abrir espaço para as múltiplas possibilidades de crescimento econômico. Integrar as culturas; tornar homogêneas as diversidades, tanto na área política, cultural e principalmente na 
econômica. Estas seriam as bases ideológicas da globalização. As diferenças culturais deveriam ser quebradas com a integração das sociedades. E, para conseguir essas "harmonias" entre os mercados mundiais, as teorias da globalização usaram vários artifícios retóricos. Um deles é um alto investimento em recursos tecnológicos, alardeados pelos meios de comunicação.

Segundo Batista (1994), deve-se observar que o termo "globalização" foi associado ao discurso Neoliberal, como promessa de um novo modo de desenvolvimento. Contudo, historicamente, o Liberalismo clássico já apregoara a supremacia da liberdade, em todas as esferas: social, política, de pensamento, de expressão, para justificar a liberação dos mercados e a livre concorrência. As inovações tecnológicas, principalmente nas telecomunicações, promoveram um processo de globalização, a partir de informações entre empresas e instituições financeiras, ligando os mercados do mundo, estreitando relações comerciais entre países e empresas favorecendo a formação de blocos econômicos que buscaram fortalecer, um mercado cada vez mais competitivo.

Nos pressupostos da análise de Batista (1994), ao se abrirem os mercados, a competição ficou livre, transações podem ser feitas e acordos comerciais fechados. O grande problema desses fatores é o fato de a concorrência suceder, entre países com poder econômico e político desiguais. Obviamente, as grandes empresas entram em países em desenvolvimento, enquanto as empresas locais, muitas vezes, não têm suporte suficiente para competir. Essa política de mercado pretende "globalizar" a economia; inserir novas tecnologias nos Estados "subdesenvolvidos", pois estes são vistos como incapazes de promover seu próprio crescimento. Nesse sentido, Batista destaca que não há uma economia internacional. Isso ocorre principalmente nas grandes economias, onde os mercados têm uma forte relação, não predominando as economias internas, mas as transações externas entre os mercados.

Muitas vezes, os países “subdesenvolvidos” ficam a mercê das políticas externas de grandes mercados, apostando na possibilidade de ingressarem na economia global. Com isso, implantam políticas econômicas voltadas para os padrões mundiais, que não atendem às necessidades locais. E, quando não se enquadram a essas políticas, são fortemente punidos pela lógica do mercado. Diante desse quadro de abertura para uma economia global, de disparidade concorrencial. Muitos países desnacionalizam suas empresas que dão mais lucro, ficando cada vez mais vulneráveis as políticas externas, comprometendo seus próprios mercados. 
Segundo Singer (1998), a globalização da economia, tornou-se responsável pela modificação internacional do trabalho. O ponto mais difícil desse processo é que os capitais são transferidos para áreas, em que o custo da força de trabalho apresenta baixos níveis, e com pouco ou nenhum benefício social para o trabalhador. Abrindo espaço para que países que possuem os direitos trabalhistas mais consolidados percam seus postos de trabalho. Levando para as ruas, milhares de trabalhadores, que experimentam, os dissabores do desemprego.

De acordo com esse mesmo autor, Singer (1998), por conta da globalização, é permitida a movimentação de capitais internacionais dentro dos países, levando a privatização e desorganização do setor público. A política monetária privilegia a estabilidade dos preços, em vista de um crescimento econômico. Em consequência disso, os países que buscam acompanhar a dinâmica da economia mundial, através da abertura de seus mercados, não conseguem passar por um processo de crescimento maior.

A globalização financeira, a mundialização da produção, o acirramento da competição internacional, o surgimento de novas tecnologias e a instabilidade da demanda forçaram a reestruturação produtiva. A redução dos custos passou a ser o objetivo principal, e despontaram como metas complementares ou auxiliares a necessidade do aumento da produtividade, a redução do espaço de produção, do tempo e do capital de giro (CALVETE, 2013, p. 189).

Para Singer (1998), as empresas que estão envolvidas em mercados globalizados encontram, no processo de reestruturação um mecanismo de defesa. Como resultado desse processo, os lugares mais elevados da hierarquia "ocupacional" são ocupados por uma pequena parcela dos trabalhadores. Somente aqueles que se destacam entre os demais, com qualificações raras, usufruem da possibilidade de ocupá-los. E são estes que poderão, dentro desse tipo de dinâmica, manter sua vaga de emprego, enquanto a grande massa de trabalhadores sem qualificação será arremessada para fora.

Nesse ínterim, os dias atuais estão envoltos de desafios, e mudanças velozes. A lógica do capitalismo e a complexa realidade social, impulsionada por uma dinâmica global, que chega a atingir todas as esferas sociais, interfere diretamente na vida em sociedade. E influencia o seu modo de pensar e agir, alterando as condições de trabalho e as relações de poder. Até a própria organização do tempo torna-se parte da dinâmica do capitalismo que, na produção, busca aproveitá-lo da melhor maneira possível para obter lucro. Já o trabalhador tenta administrá-lo, o que em muitos casos, é altamente complicado. 
De acordo com Braverman (1974) na tríade produtiva, tanto o objeto do trabalho, como o trabalho humano, e os meios que o homem dispõe para realização desse trabalho, tornam-se uma força produtiva, capaz de gerar lucro para o capitalista. Que se apropria do trabalho do outro, em benefício próprio. As relações sociais da produção decorrentes dessa tríade são entendidas como uma organização, que se estabelece, a partir da interação das pessoas e das classes na sociedade. Destarte, se visa tanto a produção material, como uma reprodução social, estabelecida nas relações de trabalho. Permitindo, uma ampliação, das relações sociopolíticas e econômicas. Todavia, o ser social não está reduzido, apenas, às relações do trabalho. Existem outros valores que transpõe a produção, como a própria capacidade que o trabalhador tem de satisfazer suas necessidades básicas.

Com o advento do capitalismo contemporâneo e o avanço tecnológico, muitas transformações ocorreram no mundo, alterando as relações sociais. No universo do trabalho, isso não foi diferente. Pois, buscando minimizar os gastos, muitas empresas criaram novas formas de contratos que, como consequência, trouxeram outros desafios à classe trabalhadora, que se viu obrigada a se adequar as novas exigências e correr contra o tempo, em vista de manterem-se ativos, e superarem as dificuldades. Um fenômeno responsável pelo surgimento dessas novas formas de trabalho é a globalização, que veio com um discurso de desenvolvimento e "bem-estar" para sociedade como um todo, mas que na verdade, trouxe consigo além do avanço, uma série de novos problemas.

O rápido avanço das novas técnicas adentrou o mundo do trabalho, despertando o fascínio pelo apanhado de possibilidades que isso poderia trazer. Mas, ignorando as consequências dessa revolução tecnológica, centralizada em níveis visíveis de dominação. Featherstone (1998) analisa que isso se explica, através de todo um processo social, cuja integração dos espaços geográficos se dá por meio do que podemos definir como "trans-sociais". Ou seja, os mecanismos ultrapassam a ideia de sociedade estatal e se deslocam, para perspectivas de um mundo mais global. Promovendo um encadeamento, de informações e conhecimentos que se move de um lugar para outro, numa posição mais autônoma. Reforçando a ideologia de que, os estados nacionais, não são capazes de se manterem afastados de políticas transnacionais.

No domínio em que se busca construir uma análise a respeito de alguns fatores sobre desenvolvimento e do complexo jogo de considerações e conflitos em torno dele, o presente trabalho, também se esforça, para levantar algumas questões, acerca da implantação, do setor de reflorestamento, no município de Açailândia, entendendo que o 
processo, também, faz parte do curso em que se dão as perspectivas sobre desenvolvimento. Destarte, o que segue, é uma tentativa de apontar algumas interpretações a partir da trajetória de implantação do setor. As consequências que isso trouxe para o município, bem como, os conflitos e as estratégias lançadas pelas empresas para permanecerem com o seu processo de produção e transcorrer as "criticas sociais" que sobre elas recaiam.

\section{SOBRE O PLANTIO DO EUCALIPTO, COMO ESTRATÉGIA DE FUGA, O PROCESSO DE IMPLANTAÇÃO DO SETOR DE "REFLORESTAMENTO" EM AÇAILÂNDIA}

Segundo Carneiro e Ramalho (2015) diversas foram às ingerências econômicas na "Amazônia Brasileira", de grandes projetos de desenvolvimento, desde o início da metade do século XX. Com isso, são introduzidos no Pará e Maranhão, especificamente no município de Açailândia e Marabá, "polos siderúrgicos", que representam mudanças significativas, tanto na "economia", como na "política e a sociedade local" de um modo geral. Até então, a "produção de ferro gusa e carvão vegetal”, estava centralizada em Minas Gerais, porém a partir dos anos 1980, há um deslocamento para a região da "Amazônia Oriental”. Esse processo de mudança ocorre, por alguns fatores significativos, dentro os quais estão, como a "isenção fiscal e subsídios", cedidos pelo "governo federal" no domínio do "Programa Grande Carajás" e, também, a criação de uma "infraestrutura para o escoamento do minério de ferro da mina de Carajás", através de uma ferrovia e do porto de Ponta da Madeira em São Luís (MA)” pela Companhia Vale do Rio Doce (Ibid, 2015 p. 15).

Junto aos grandes empreendimentos, vieram também as inúmeras expectativas de desenvolvimento e criação de novos postos de trabalho, que a princípio são encarados com bons olhos. Todavia, com o decorrer do processo, o que se percebeu foi uma série de problemas sociais relacionados à criação de trabalhos precários, com situações que envolviam relações de trabalho análogas a escravidão. Assim como situações que circundavam contextos de "degradação do meio ambiente". Um transcurso que levou a mobilização dos mais variados agentes, tanto do poder público, como da comunidade local, a fim de combater, tanto as situações de trabalho precário, com o uso da mão de obra escrava, e a destruição dos recursos naturais.

Com a implantação e ampliação do "polo siderúrgico", nos pressupostos de Assis e Carneiro (2012), a fabricação do carvão vegetal tornou-se um dos problemas 
ambientais de maior relevância, tanto nos estado do Pará, como no estado do Maranhão. Com os incentivos, o setor siderúrgico foi crescendo, contudo, sem dispositivos de controles que pudessem impedir os alarmantes problemas sociais e ambientais. Os “dados" apontados pelos autores, que trazem estimativas acerca da "produção do carvão vegetal", demonstram índices preocupantes com relação ao nível de destruição causados pela "atividade", desenvolvida no setor. Desse modo, "a fragilidade dos mecanismos de controle possibilitou a criação de uma rede de favorecimento para a produção e transporte ilegal do produto na região difícil de ser combatida. Entre os anos de 2006 e 2009, a oficina regional do Instituto Brasileiro de Meio Ambiente e Recursos Naturais Renováveis (IBAMA) em Marabá capturou aproximadamente 196.630 m de carvão ilegal em 31 municípios de sua jurisdição" (Ibid, p. 362).

No entendimento em que se constrói a análise, a partir do aspecto da existência de algum mecanismo, a ser utilizado como ferramenta de combate aos danos ambientais causados pelo setor siderúrgico (ASSIS; CARNEIRO, 2012), indica o "artigo 21 do código florestal", que estabelece, que as "empresas siderúrgicas", ou empresas de outro porte que fazem uso do "carvão vegetal" e utilizam "matérias primas florestais", assim como trabalham no seu carregamento, se responsabilizem por "implantar áreas de bosques próprios para a exploração racional” (p. 62).

Com o aumento do setor siderúrgico na Amazônia, alguns problemas começaram a entrar em pauta. De acordo com Carneiro (2008), o crescimento das empresas estava ligado a situações que envolviam o trabalho escravo. Isso ocasionou uma série de reivindicações dos mais diferentes agentes, que começaram a exigir dos produtores de ferro gusa uma postura diferente. As primeiras censuras e reivindicações, segundo Sutton (1994), Carneiro (2008) e FILHO et al. (2011), em relação ao trabalho escravo, surgiram através de organizações não governamentais, dentre elas a Comissão da Pastoral da Terra e a Anti-Slavery International. Que juntamente com outros movimentos sociais, se mobilizaram para combater o trabalho escravo.

Parâmetros que elencam os mais diferentes pontos de vista acerca da funcionalidade de tais medidas para o favorecimento de um processo de preservação eficaz, são colocadas em pauta, visto que, a iniciativa pode apenas contemplar as necessidades dos empresários, e em contrapartida, continuar causando danos sociais e ambientais. Um bom exemplo é a própria utilização da monocultura, como forma de "reflorestamento". Nessa lógica, 
Um dos principais pontos de divergência relacionados a este tema se refere ao tipo de bosque a ser implantado: bosques diversificados com espécies nativas ou monocultivos com espécies de arvores exóticas. Uma vez que as empresas tendem a implantar monoculturas, arvores com espécies exóticas de crescimento rápido, grupos locais ligados a movimentos sociais e entidades de representação da sociedade civil se posicionam contra (Carneiro, 2008 p. 362 e 363).

A profusão de posicionamentos, que se mostram partidários e, portanto, apoiadores de iniciativa de utilização de mecanismos de "tecnologias limpas". Dão, de certo modo, a permissão para que os empresários, continuem o processo de produção. Por outro lado, aqueles que mantêm um posicionamento oposto, por acreditarem, que esse tipo de iniciativa, em nada colabora para amenizar e combater os impactos ambientais, retardam o processo de devastação. Logo, Silva e Barbosa (2012) enumeram a movimentação das mais variadas "correntes", que se mantém "contrárias", a esse tipo de iniciativa. O que ocorre, em linhas gerais, seguindo o pensamento dos autores, é que quando é implantado esse tipo de "projeto", pouco, ou quase nada é feito para monitorar as empresas, como é o caso do plantio do eucalipto ${ }^{3}$. Isso coloca em debate, os privilégios e alvarás que os empresários obtêm com esse tipo de iniciativa para continuarem ampliando seu processo de produção e, simultaneamente, os danos "ambientais" e "sociais".

A participação das mais variadas correntes de pensamento, ou dos mais variados agentes, nas tomadas de decisões é algo que nos remete a várias questões políticas e sociais. E nos leva a buscar entender todo contexto histórico da implantação do processo de participação democrática. Muitos falam de democracia nos dias atuais, porém, há poucos embasamentos teóricos que sustentem essa ideia de participação democrática nas sociedades modernas capitalistas. Sabe-se que embora se criem mecanismos que possam vir a garantir a participação das pessoas nas decisões do Estado, sempre há por trás outros mecanismos que burlam essa participação das pessoas nas tomadas de decisões, e mascaram as intenções de manipulação do poder, tanto de pequenos grupos dominantes ou até mesmo dos próprios representantes do Estado.

Entre os inúmeros fatores que podem ser destacados, para a mudança de estratégias no setor siderúrgico da Amazônia, como destaca Carneiro (2008) e Pitombeira (2011), está o Termo de Ajuste de Conduta (TAC) firmado pelas empresas

\footnotetext{
${ }^{3} \mathrm{~A}$ preocupação das comunidades em áreas de plantio de eucalipto é justamente quanto ao aumento dessas áreas devido aos novos incentivos proporcionados ao setor, o que só acarretaria mais prejuízos às populações que convivem diariamente com os problemas causados por ele (SILVA; BARBOSA, 2012, p. $11)$.
} 
do setor siderúrgico do Maranhão, no ano de 1997, juntamente com o Ministério Público do Trabalho e a Procuradoria Regional do Trabalho. Consequência das vistorias feitas pela equipe móvel do Ministério do Trabalho e Emprego (MTE) nas fazendas, que tinham como atividade a produção de carvão. Com as vistorias, se constatou as condições precárias e degradantes de trabalho e, também, um encadeamento, de devastação ambiental. Em seguida, é lançada uma "Carta-compromisso", que visava o compromisso das empresas, em acabar com relações que envolviam o trabalho escravo e as formas irregulares, de utilização dos recursos naturais.

Nesse aspecto, segundo Carneiro (1997), com as denúncias sobre o trabalho escravo e a devastação ambiental, as empresas do setor siderúrgico, precisaram acionar novas estratégias, que pudessem torna legítimas, sua atuação no setor, fugindo as "críticas sociais", que recaíam sobre elas. Uma das estratégias foi criar o setor de reflorestamento, para produção do carvão à base de eucalipto, através da terceirização de serviços, no plantio, colheita, transporte e manutenção. Nesse momento os trabalhadores saem de uma situação de trabalho escravo e passam para uma situação de trabalhador formalizado, de carteira assinada, mas através de um processo de terceirização.

Segundo os estudos realizados por Carneiro (2015), as empresas passaram então a produzir seu próprio carvão, a partir do eucalipto, não comprando mais de produtores independentes. Mas por outro lado, o setor de reflorestamento, no plantio e na colheita, passou a utilizar mão de obra terceirizada. Contudo, é importante ressaltar, que tanto as relações de trabalho, como os contextos de preservação ambiental, ainda, são questões a serem observadas nesse contexto de novas estratégias, visto que a terceirização de serviço tem demonstrado índices de precarização das formas de trabalho. O uso de monoculturas tem consequências alarmantes tanto para o solo como para o trabalhador que está envolvido diretamente no seu plantio, por causa da manipulação de "produtos químicos", durante o processamento da atividade.

Em contextos em que se observa, o aumento do uso de monoculturas, e de suas variadas formas de utilização pela "cadeia produtiva", no Maranhão Assis e Carneiro, (2012) ressaltam que o "plantio do eucalipto" está agregado aos contextos de inserção do setor siderúrgico que, por sua vez, causou embates e coalizões no processo de disposições da "propriedade de terras". O que se nota nos levantamentos acerca do aumento da fabricação do "carvão", segundo a lógica em que se compõe a mesma análise, é que isso afetou diretamente o "mercado" local de divisão de "terras". Além 
disso, no que segue a análise dos autores, existem os problemas, que giram, em torno, dos danos causados pelo uso de "produtos químicos" que é empregado na "manutenção" e composição das plantações de eucalipto. O dano maior é que, os "trabalhadores rurais", sofrem uma sucessão de "envenenamentos" no processo de plantio e manutenção do eucalipto.

\section{CONSIDERAÇÕES FINAIS}

Ao longo de todo o trabalho, percebe-se que, as discussões, acerca do desenvolvimento demonstram as mais variadas perspectivas, que problematizam sua idealização como fator preponderante e necessário a todos os espaços. A dicotomia que separa os países centrais dos periféricos é construída a partir do próprio sentido que é dado a busca de hegemonia dos ditos países "desenvolvidos”, mais especificamente dos Estados Unidos. A ideia de "falta", de uma cura aos problemas emergentes dos países "subdesenvolvidos", legitimou a atuação de iniciativas, que buscam um contínuo crescimento econômico, como forma de aplacar as desigualdades sociais. No discurso, os aspectos sobre os benefícios do "desenvolvimento" aparecem continuamente como a solução para os problemas sociais. Na prática, os contextos são diferentes, em vez de avançar, devasta, de diminuir ou eliminar as desigualdades sociais, faz aumentá-la ainda mais.

As críticas construídas, em torno de um processo de exploração dos recursos naturais, buscaram combater de forma factual os impactos causados pelos inúmeros projetos de desenvolvimento. Todavia, não se viu um processo reverso, capaz de pensar iniciativas de manutenção da vida sem os avanços das forças produtivas. O que se verifica é o inverso. Pensar a vida sem formas de crescimento econômico parece não ganhar sustentação, já que a ideia de desenvolvimento tornou-se tão impregnada nas estruturas socais e econômicas que se figura ser impossível viver sem ele. O máximo que as iniciativas combativas conseguem é uma configuração de outros codinomes, que são dados à noção de desenvolvimento. Um deles é o de "sustentável” que, a princípio, teve intuitos de conter ou pleitear a o agravamento da degradação ambiental. Contudo, o que ocorre é que todas as novas roupagens que são dadas à noção de desenvolvimento mascaram os aspectos reais de sua intenção.

Ou seja, se fala de desenvolvimento "sustentável", "humano", "participativo" e entre outros, mas o que ocorre, é uma manutenção das mesmas dimensões de seus ideais 
econômicos. Fixa-se um jogo de palavras que busca conciliar crescimento com preservação, mas que, estruturalmente falando, é complexo. A nova roupagem, nesse sentido, funciona mais como uma fachada do que como uma forma de pensar iniciativas menos degradantes, que possam garantir de fato a preservação dos recursos naturais e consequentemente, "bem-estar social".

A retórica da globalização mostra que existe interesses muito específicos, no processo de integração de caráter econômico, social, cultural e político entre diferentes países. Por conseguinte, ela é implantada no setor financeiro, a fim de favorecer a liberação das reservas de mercado e dos fluxos de capital. E, concomitantemente, funciona como um mecanismo ideológico, utilizado para afirmar e reafirmar concepções acerca da necessidade de um progresso contínuo, sobre a atual estrutura da realidade. É um encadeamento que afeta diretamente o mercado de trabalho e torna desiguais as formas de competição entre os países ditos "periféricos", em relação àqueles que se encontram no "centro".

O uso da monocultura como forma de "reflorestamento" tem crescido muito nos últimos anos. É utilizada para os mais variados interesses, um deles é a produção de carvão, que atende as necessidades do setor siderúrgico. O que é deixado de lado são os problemas relevantes que projetos como esses causam às questões sociais e ambientais, e faltam medidas para controlar seus efeitos.

Como já foi exposto, em parágrafos anteriores, Com a ampliação, em longa escala, do "parque industrial" no município de Açailândia, cresce também a necessidade de um consumo maior do carvão vegetal, que de início era fornecido por pequenos produtores independentes que causaram sérios danos sociais e ambientais. Atrelado a isso, vieram as "criticas sociais" que denunciavam os altos níveis de devastação ambiental e o uso de formas precárias de trabalho, com situações análogas à escravidão. Mesmo as empresas acionando novas estratégias para escapar das "críticas sociais", com a criação do setor "reflorestamento" à base da plantação do eucalipto, é fundamental problematizar, esse tipo de iniciativa, dado que, também tem suas consequências diretas, tanto para o meio ambiente como para os trabalhadores e a população de um modo geral. E, portanto, cabem sempre novos levantamentos sobre as formas de pensar a vida a partir de iniciativas que realmente possam favorecer condições dignas de sobrevivências às populações e incentivem a permanência e conservação dos recursos naturais. 


\section{REFERÊNCIAS BIBLIOGRÁFICAS}

ASSIS, W. S.; CARNEIRO, M.D.S. O uso do carvão vegetal como fonte de energia para o parque siderúrgico de Carajás: controvérsias sociais, ambientais e econômicas. In: PORRO, R.; TONI, F.(Org.). Energia na Amazônia. Belém: Iniciativa Amazônica, 2012.

BRAVERMAN, Harry. Trabalho e Capital Monopolista, a Degradação do Trabalho no Século XX 3。 Edição Nova York, Estados Unidos. Monthaly Review Press, 1974.

CALVETE, Cássio da Silva. A disputa pelo tempo de trabalho. Al. In: KREIN, José Dari et al. (org.). Regulação do Trabalho e Instituições Públicas, São Paulo, Vol. 1 e 2, Fundação Perseu Abramo, 2013.

CARNEIRO, Marcelo Sampaio. "Do Latifúndio Agropecuário à Empresa Latifundiária Carvoeira". In COELHO, Maria Célia Nunes; COTA, Raymundo Garcia. (Org.). 10 anos da Estrada de Ferro Carajás. Belém UEPA/NAEA, Supercores, Belém, 1997.

Terra, trabalho e poder: conflitos e lutas sociais no

Maranhão contemporâneo. São Paulo: Annablume, 2013.

FEATHERSTONE, Mike (coord.). Cultura Global. Nacionalismo, globalização e modernidade. Trad. de Attílio Bruneta. Petrópolis: Vozes, 1998.

RAMALHO, J. R.; CARNEIRO, M. .S. Trabalho e siderurgia na Amazônia brasileira. In: CARNEIRO, M.S.; RAMALHO, J.R. (Orgs). Ações coletivas em complexos minero-metalúrgicos: experiências na Amazônia e no Sudeste brasileiro. São Luis: EDUFMA, 2015. (no prelo)

SINGER, Paul. Globalização e Desemprego: Diagnóstico e Alternativas. São Paulo, Contexto, 1998.

SUTTON, Alison. Trabalho Escravo. Um elo da cadeia da modernização no Brasil de hoje. Anti-Slavery International. Edições Loyola: São Paulo, 1994

CARNEIRO, M. S; RAMALHO, J. R. A crise econômica mundial e seu impacto sobre o setor siderúrgico maranhense: relações entre o desempenho recente das empresas guseiras e o desemprego no município de Açailândia. In: CARNEIRO, M.D.S.; COSTA, W. C. (Org.). A terceira margem do rio: ensaios sobre a realidade do Maranhão no novo milênio. São Luís: EDUFMA, 2009, v. 1, p. 37-48.

CARNEIRO, Eder Jurandir. Política ambiental e a ideologia do desenvolvimento sustentável. In: ZHOURI, Andréa; LASCHEFSKI, Klemes; PEREIRA, Doralice Barros. A insustentável leveza da política ambiental - desenvolvimento e conflitos socioambientais. Belo Horizonte: Autêntica, 2005. P. 27-47.

ESTEVA, Gustavo. Desenvolvimento. In: SACHS, Wolfgang (editor). Dicionário do desenvolvimento: guia para o conhecimento como poder. Trad. Vera Lúcia M.; JOSCELYNE, Susana de GYALOKAY e Jaime A. CLASEN. Petrópolis, RJ: Vozes, 2000. p. 59-83.

FURTADO, Celso. Raízes do subdesenvolvimento. Rio de janeiro: Civilização Brasileira, 2003.

SHIVA, Vandana. Recursos Naturais. In: SACHS, Wolfgang (editor). Dicionário do desenvolvimento: guia para o conhecimento como poder. Trad. Vera Lúcia M.; JOSCELYNE, Susana de GYALOKAY e Jaime A. CLASEN. Petrópolis, RJ: Vozes, 2000. p. 300-316.

ZHOURI, Andréa; LASCHEFSKI, Klemes. Desenvolvimento e conflitos ambientais: um novo campo de investigação. In: ZHOURI, Andréa; LASCHEFSKI, Klemes (Org.). Desenvolvimento e conflitos socioambientais. Belo Horizonte: Editora UFMG, 2010. p. 11-31. 
ZHOURI, Andréa; OLIVEIRA Raquel. Quando o lugar resiste ao espaço: colonialidade, modernidade e processos de territorialização. In: ZHOURI, Andréa; LASCHEFSKI, Klemes (Org.). Desenvolvimento e conflitos socioambientais. Belo Horizonte: Editora UFMG, 2010. p. 439-462.

BATISTA, Paulo N. (1994) O Consenso de Washington: a visão neoliberal dos problemas da América Latina. Caderno Dívida Externa N 6, 1994.

CARNEIRO, Marcelo Sampaio. Crítica social e responsabilização empresarial: análise das estratégias para legitimação da produção siderúrgica na Amazônia Oriental. Caderno CRH. Salvador: v. 21, n. 53. 323-336, 2008.

.Trabalhadores em carvoarias na Amazônia Oriental:

distante da cidadania, além da mera exclusão. Revista Sociedade em Debate. V. 8, $\mathrm{n}^{\circ}$ 2, UCPEL, Rio Grande do Sul, 2002.

FILHO, A.; MASSON, N.; COSTA, R.. Atlas político-jurídico do trabalho escravo contemporâneo no Maranhão. Açailândia/Imperatriz: CDVDHCB/ÉTICA, 2011.

MOURA, F. A. Escravos da Precisão: economia familiar e estratégias de sobrevivência de trabalhadores rurais em Codó (MA). 2006. Dissertação (Mestrado em Ciências Sociais)-Universidade Federal do Maranhão, São Luís, 2006.

PITOMBEIRA, K. S. A construção da responsabilidade empresarial n Pólo Siderúrgico Carajás: o caso Instituto Carvão Cidadão. 2011. Dissertação (Mestrado em Ciências Sociais)- Universidade Federal do Maranhão, São Luís, 2011.

BATISTA JR. Paulo Nogueira (1998) Mitos da "globalização". Estudos Avançados 12, disponível em (http://www.scielo.br/pdf/ea/v12n32/v12n32a12.pdf). Acessado em Outubro de 2015.

ESCOBAR, Arturo. O lugar da natureza e a natureza do lugar: globalização ou pósdesenvolvimento? In: A colonialidade do saber: eurocentrismo e ciências sociais. Perspectivas latino americanas. Edgardo Lander (org). Colección Sur Sur, CLACSO, Ciudad Autónoma de Buenos Aires, Argentina. Setembro 2005. p. 63-79. Disponível em : http://bibliotecavirtual.clacso.org.ar/ . Acessado em janeiro de 2016.

RADOMSKY, Guilherme Francisco Waterloo. Desenvolvimento, pós-estruturalismo e pós-desenvolvimento; a crítica da modernidade e a emergência de "modernidades" alternativas. Revista Brasileira de Ciências Sociais. Vol. $25 \mathrm{~N}^{\circ} 75$, fevereiro de 2011. P. 149-193. Disponível em: http.//portal.anpocs.org/portal/índex.php?option=com content \&view=article\&id=161:rbcs-75\&catid=69:rbcs\&Itemid=399. Acessado em 08/09/2014.

SILVA, Tathiane Paraíso da; BARBOSA, Rômulo Soares. Nova Dinâmica de expansão da monocultura de eucalipto: produção de carvão vegetal e MDL. UNIMONTE, 2012. Disponível em: https:/www.google.com.br/url?sa=t\&source=web\&rct=j\&url=http://congressods.com.br /terceiro/índex.php/desigualdades-e-ambiente-conflitos-socioambientais/341-novadinamica-de-expansão-da-monocultura-deeucalipto-producao-de-carvao-vegetal-e-mdl. Acessado em Janeiro de 2016.

ZHOURI, ANDRÈA; OLIVEIRA, Raquel. Development and environmental conflicts in Brazil: challenges for anthropology and anthropologists. Vibrant. V. 9, n.1, junho de 2012. p. 181-208. Disponível em: http://www.vibrant.org.br/issues/v9n1/andrea-zhouriand-raquel-oliveira-development-and-environmental-conflicts-in-brazil/. Acessado em 08/09/2014.

Recebido para avaliação em 20/06/2016.

Aceito para publicação em 20/07/2017. 